\title{
Pertinência da normativa estadual e distrital sobre logística reversa aplicada ao setor de medicamentos no Brasil
}

State laws about reverse logistics applied to the drug sector in Brazil

Relevancia de leyes provinciales sobre logística inversa aplicada al sector de medicamentos en Brasil

RESUMO. Introdução: a forma inadequada do manejo dos resíduos de medicamento desperta a preocupação dos setores do meio ambiente e da saúde. Com a falta de norma federal vigente que estabeleça como proceder o recolhimento e descarte corretos, os estados produziram suas regras. O estudo analisa a profundidade material das normas, a conformidade com os regulamentos federais vigentes e a adaptação após a promulgação da Política Nacional de Resíduos Sólidos. Metodologia: foi uma pesquisa exploratória com análise quali-quantitativa dos regulamentos estaduais sobre logísitica reversa de medicamentos. Resultados: foram encontradas 28 normas de 18 unidades federadas, promulgadas de 1994 a 2015. Observou-se o predomínio de lei ordinária como espécie normativa (93 \%) e duas abordagens distintas: as mais antigas estabelecem o compromisso entre indústria e estabelecimento para produto não comercializado, enquanto que, as mais recentes, com o advento da Política Nacional de Resíduos Sólidos, estendem a responsabilidade do correto descarte a todos os agentes envolvidos, inclusive ao consumidor. As normas variaram na objetividade quanto ao mérito, foram insuficientes nos temas de gestão administrativa e de projetos, responsabilidade dos agentes e gerenciamento dos resíduos, capacitação da população e não atenderam as necessidades locais. Conclusão: apesar de os regramentos, em geral, não serem completos, haver lacunas e darem um tratamento superficial, algumas normas trazem contribuições relevantes para a efetiva e eficiente implementação da política nacional de descarte de medicamentos. Palavras-chave: Medicamento, Resíduo de Serviço de Saúde, Logística Reversa, Política Nacional de Resíduos Sólidos, Legislação Ambiental (Brasil).

ABSTRACT. Introduction: improper handling of drug residues aroused the concern of the environment and health sectors. With the lack of federal rules and disposal medicines, states have produced their owns. Methodology: the study analyzes the depth of these rules, compliance with existing federal regulations and adaptation to the National Solid Waste Policy. It was an exploratory research with qualitative and quantitative analysis of state regulations on reverse logistics medications. Results: were found 28 rules of 18 federal units, enacted from 1994 to 2015. There was a predominance of regular law as normative species (93\%) and two different approaches: the oldest establish a compromise between industry and pharmacies for not marketed products, while the latest, with the advent of the National Solid Waste Policy, extends the disposal responsibility to all

${ }^{1}$ Graduada em Ciências Biológicas - Universidade de Brasília. Brasília, Brasil. E-mail: tinacgt@gmail.com 
members of the productive chain, including consumers. Conclusion: the rules ranged in objectivity, were insufficient regarding matters of administration and projects, responsible waste management and training, and did not meet local needs. Although not complete, with gaps and superficial treatment, some regulations bring significant contributions to the effective and efficient implementation of the national policy of drug disposal.

Keywords: Medicine, Medical Waste, Reverse Logistic, National Solid Waste Policy, Environmental Law (Brazil)

RESUMEN. Introducción: la forma inadecuada de tratamiento de residuos de medicamentos despertó la preocupación de los sectores de medio ambiente y salud. Con la falta de norma federal que estabeleca cómo hacer la recogida y eliminación de esos productos, las provincias han producido sus propias reglas. Metodología: el estudio analiza la profundidad de esas normas, el cumplimiento con las regulaciones federales existentes y su adaptación, después de la promulgación de la Política Nacional de Residuos Sólidos. Es una investigación exploratoria con análisis cualitativo y cuantitativo de los reglamentos provinciales sobre logística inversa de medicamentos. Resultados: fueron encontradas 28 normas jurídicas de 18 unidades federales, promulgadas entre 1994 y 2015. Hubo un predominio de la ley regular en cuanto a la especie normativa elegida (93\%) y dos enfoques distintos: las más antiguas establecen un compromiso entre la industria el establecimiento farmacéutico sobre los productos no comercializados, mientras que las últimas, posteriores al advenimiento de la Política Nacional de Residuos Sólidos, extienden la responsabilidad sobre la disposición para todas las partes involucradas, incluidos los consumidores. Las normas variaron en la objetividad en los méritos, no fueron suficientes en las áreas de administración y proyectos, gestión responsable de los residuos e el entrenamiento de la población, y no responden a las necesidades locales. Conclusión: aunque, en general, no sean completas, contengan lagunas normativas y dan tratamiento superficial a la mayoría de las materias, algunas regulaciones traen importantes contribuciones a la aplicación efectiva y eficiente de la política nacional sobre esa materia.

Palabras-Ilave: Medicina, Residuo Sanitarios, Logística Inversa, Política Nacional de Residuos Sólidos, Legislación Ambiental (Brasil).

\section{Introdução}

O medicamento é definido pela Lei no 5.991, de 17 de dezembro de 1973, e classificado como resíduo do grupo B pela Resolução da Diretoria Colegiada (RDC) no 306, de 7 de dezembro de 2004, da Agência Nacional de Vigilância Sanitária (ANVISA). Seu descarte inadequado pode apresentar risco à saúde pública e ao meio ambiente devido às suas características de inflamabilidade, corrosividade, reatividade e toxicidade (1).

Brasil é um dos maiores mercados do setor farmacêutico e, em 2009, ocupava o 9응 lugar no ranking do mercado mundial segundo o Intercontinental Marketing Services 
Health (IMS)², em 2010 (2). Essa posição deve-se não apenas ao elevado consumo, mas, também, à automedicação, à dispensação não condizente com a duração do tratamento, ao não fracionamento na dispensação (3), à interrupção do tratamento (4), à distribuição aleatória de amostras-grátis (5), ao gerenciamento inadequado de estoques pelas empresas e estabelecimentos de saúde e à carência de informação da população (1) fatores esses que favorecem a ocorrência de sobras e de vencimento de medicamento.

Quando não for possível a reutilização, o medicamento inutilizado deve ser submetido a tratamento específico para seu descarte (4). Em último caso, deve ser disposto em aterro de resíduos perigosos, a menos que em estado líquido, admitindo-se o lançamento, nas redes coletoras de esgoto, apenas de líquidos que não ofereçam riscos de manejo e de disposição final (6), uma vez que atendam às diretrizes estabelecidas pelos órgãos ambientais.

Essa última disposição tem sido objeto de críticas, pois não há como garantir, em todos os casos, a inocuidade à saúde e ao meio ambiente dessas substâncias (5).

Em razão da carência, no país, de postos de coleta (7), de aterros sanitários e de incineradores licenciados (1), o descarte inadequado de medicamentos acontece no lixo doméstico ou na rede de esgoto. Por isso, cerca de $20 \%$ de toda a produção farmacêutica no Brasil vai para o lixo comum (3), estimando-se que sejam produzidos, no país, entre 10 e 28 mil toneladas de resíduos de medicamentos a cada ano e que o volume de resíduos domiciliares de medicamentos esteja algo entre 4,1 e 13,8 toneladas ao ano (2).

Em vista disso, a forma correta do manejo de resíduos tem tomado a atenção da sociedade, posto que se identifica, cada vez mais, a presença de fármacos no meio ambiente. A grande preocupação em relação a resíduos de medicamentos na água, diz respeito aos potenciais efeitos adversos para a saúde humana e animal, causando desequilíbrios nos ecossistemas. Mesmo que as concentrações de alguns fármacos sejam baixas, a combinação destas substâncias pode provocar efeitos pronunciados devido ao mecanismo de ação sinérgica (8). A interação pode ser desde agonista total a agonista inverso (9).

Esses efeitos podem ser detectados em qualquer nível da hierarquia biológica,

2 - Intercontinental Marketing Services Health. Pharmerging shake-up: new imperatives in a redefined world. Norwalk: IMS, 2010 apud (2). 
podendo ocasionar destruição de células, teratogenicidade e mutação (10). As classes de fármacos mais preocupantes são os antimicrobianos, os quimioterápicos antineoplásicos e os hormonais (11). Os antibióticos, por exemplo, podem desenvolver bactérias resistentes no meio ambiente, visto a facilidade desses micro-organismos em trocar material genético. Os estrógenos, perturbadores endócrinos, podem afetar o sistema reprodutivo dos peixes, com feminilização dos machos (3). Os antineoplásicos e imunossupressores são potentes agentes mutagênicos (4).

Diante do exposto, vivencia-se, no Brasil, um amplo debate intersetorial, envolvendo governo, setores acadêmico e empresarial e entidades civis - em consonância com a promulgação da Lei oㅜ 12.305, de 2 de agosto de 2010, que institui a Política Nacional de Resíduos Sólidos (PNRS) - sobre a instituição do instrumento de logística reversa no setor de medicamento, com objetivo de estabelecer responsabilidade compartilhada de todos os atores do ciclo de vida dos produtos, implementado e operacionalizado por meio de acordos setoriais ou por termos de compromisso (12).

A logística reversa é, segundo o art. 13 do Decreto o 7.404, de 23 de dezembro de 2010, (13) que regulamenta a PNRS:

\begin{abstract}
Instrumento de desenvolvimento econômico e social caracterizado pelo conjunto de ações, procedimentos e meios destinados a viabilizar a coleta e a restituição dos resíduos sólidos ao setor empresarial, para reaproveitamento, em seu ciclo ou em outros ciclos produtivos, ou outra destinação final ambientalmente adequada [independentemente do serviço público de limpeza urbana e de manejo dos resíduos sólidos.
\end{abstract}

$\mathrm{O}$ art. 33, $\S 1^{\circ}$ da PNRS estende a obrigação a outros produtos perigosos, considerando, prioritariamente, o grau e a extensão do impacto à saúde pública e ao meio ambiente dos resíduos gerados (12). A inclusão implícita do setor de medicamentos ao cuidado com o descarte pela PNRS, bem como a desídia dos segmentos geradores de resíduos em efetuar o correto descarte - que alegam o alto custo da sua implementação, apesar de este ser mitigado com os benefícios a longo prazo - (1) atrasam a tomada de decisão.

A obstinação em incorporar o medicamento ao descarte deveria ter sido superada a mais tempo, pois não é de hoje a inserção da matéria aos códigos. A Lei Orgânica da Saúde, Lei oㅡ 8.080, de 19 de setembro de 1990, por exemplo, já estabelecia, em seu art. 6o, incisos V e VI, como atribuições do SUS, a colaboração na proteção do meio ambiente 
e a formulação da política de medicamentos. Mas diante da crescente preocupação com o meio ambiente, insere-se, na agenda governamental, a elaboração da logística reversa com participação de todo o ciclo produtivo do medicamento, a fim de definir regras para a devolução dos resíduos (14).

Como o Brasil ainda não dispõe de legislação nacional específica para o gerenciamento de resíduos de medicamentos com a abrangência e alinhamento à PNRS, o assunto é abordado em normas gerais ou específicas para determinados setores da cadeia de produção farmacêutica, como a RDC nº 306/2004 da Anvisa (6), que dispõe sobre o Regulamento Técnico para o Gerenciamento de Resíduos de Serviços de Saúde, o Manual de Gerenciamento de Resíduos Serviço de Saúde (MGRSS), da Anvisa, (11) e a Resolução no 358/2005 do Conselho Nacional do Meio Ambiente (Conama) (16), que dispõe sobre gerenciamento e destinação final dos resíduos dos serviços de saúde. Eles esclarecem os critérios de descarte de acordo com as propriedades dos fármacos (5), mas não tratam da responsabilidade compartilhada e harmônica de cada ente da cadeia produtiva, não incluem o usuário nas incumbências e não abordam os resíduos de medicamentos domiciliares (14).

Apesar do lapso regulamentar nacional, existem alguns estados e municípios que possuem programas de coleta de medicamentos. Pois o ordenamento jurídico constitucional, no art.18, esclarece a autonomia político-administrativa entre os entes federados. Admite-se titular concorrentemente para equilíbrio e isonomia material (17), em razão da repartição constitucional verticalizada de competências. Enquanto a União é limitada a estabelecer normas gerais, os estados legislam suplementarmente, ou em sua plenitude, quando da omissão de lei federal (18).

$\mathrm{O}$ art. 23 da Constituição Federal diz ser competência comum da União, dos estados, do Distrito Federal e dos municípios cuidar da saúde, proteger o meio ambiente e combater a poluição em qualquer de suas formas. $O$ art. 24 estabelece a competência da União, estados e Distrito Federal para legislar concorrentemente sobre e proteção e defesa da saúde, do solo e controle da poluição. Apesar da omissão em legislar, na repartição de competências estabelecida no artigo 24, os municípios são entes federados dotados de capacidade legislativa sobre assuntos de interesse local, conforme artigo 30 , parágrafo $1^{\circ}(18)$. 
A PNRS atribui a União a implementação da gestão integrada de resíduos sólidos em regime de cooperação com os demais entes, encorajando-os a fazerem seus planos, que, inclusive, são requisitos para descentralização do recurso para a gestão da política (12). Com esse modelo, torna-se possível observar as especificidades e necessidades locais.

Considerando o pressuposto de que, no âmbito da legislação concorrente, as leis federais ditam normas gerais e a relevância do regramento estadual e distrital para implementação desse sistema jurídico; interessa analisar a profundidade material das normas dos estados, visto sua atribuição em especificar sobre o assunto; verificar se normas encontradas estão em conformidade com os regulamentos federais vigentes; se foram adaptadas após a promulgação da PNRS; e se a técnica legislativa garante clareza e objetividade adequada para a eficácia e segurança na operação do processo.

Interessa, especialmente, esclarecer se as normas vigentes tiveram avanços após a PNRS entrar em vigor, atentam para as especificidades locais, o detalhamento do processo e da matéria são adequados e todos os agentes envolvidos no processo produtivo estão sujeitos a obrigações.

\section{Metodologia}

Tratou-se de uma pesquisa exploratória com análise quali-quantitativa de legislação estadual e distrital sobre logísitica reversa de medicamentos.

O levantamento da legislação foi feito nos bancos de dados de informação legislativa mantidos pelas assembleias legislativas dos estados pela Câmara Legislativa do Distrito Federal e pela Casa Civil da Presidência da República. Também foram consultados os bancos de dados: Interlegis, do Senado Federal; Saúde Legis, do Ministério da Saúde; e LexML, além dos diários oficiais dos Estados e do Distrito Federal.

Foram usadas como argumentos de pesquisa as expressões: 'política estadual de medicamento', 'política de resíduos sólidos', 'resíduo domiciliar', 'resíduo doméstico perigosos', 'recolhimento de medicamento', 'descarte de medicamento/de fármaco', 'medicamento vencido', 'logística reversa de medicamento', 'destino final de medicamentos', 'medicamento no meio ambiente', 'coleta de medicamento'. Foram consideradas apenas aquelas normas com conteúdo relacionado ao descarte de medicamento 
Foram analisados os aspectos formais (espécie normativa, data de entrada em vigor, racionalidade linguística, técnica e jurídico-formal) e o mérito (gestão, setores responsáveis, gerenciamento dos resíduos e capacitação); consoante com a Política Nacional de Resíduos Sólidos (PNRS) (12), o Manual de Gerenciamento de Resíduos de Serviço de Saúde (MGRSS) da Anvisa (11), a RDC no 306/2004 da Anvisa (6), e a Resolução no 358/2005 do CONAMA (gerenciamento e destinação final de Resíduos de Serviço de Saúde) (16).

Foi feita uma análise do conteúdo material das normas, verificando-se a clareza, objetividade e adequação das normas aos regulamentos vigentes, e investigou-se sua compatibilidade com regramentos federais e a viabilidade de implementação do programa de recolhimento de medicamento, considerando os dispositivos legais existentes e a realidade sanitária do Brasil.

\section{Resultado e Discussão}

Foram encontradas 28 normas jurídicas sobre descarte de medicamento, correspondente a 18 unidades federadas. (Quadro 1) A Lei no 7.735/2004, do Espirito Santo, e a Lei oㅜ 13.039/2001, do Paraná, foram ab-rogadas por leis ulteriores, sendo que, no primeiro caso, a lei revogadora (Lei no 8.471/2007 do Espírito Santo) apenas tratou da revogação. Para efeito de análise estas três normas foram desconsideradas.

A espécie normativa sobejamente encontrada foi a lei ordinária. Apenas duas unidades federadas se utilizaram de outras espécies: uma portaria e uma instrução normativa, ambas com entrada em vigor em 2015. A data de adoção das normas variou de 1994 a 2015.

Quadro 1 - Normas jurídicas estaduais sobre descarte de medicamento.

\begin{tabular}{|l|l|l|}
\hline Unidade federada & Norma jurídica & Ementa \\
\cline { 2 - 3 } Acre & Lei no $2.720 / 2013$ & $\begin{array}{l}\text { Cria o Programa Estadual de Coleta de Medicamentos Vencidos ou } \\
\text { Estragados. }\end{array}$ \\
\cline { 2 - 3 } & Lei no $1.401 / 2001$ & $\begin{array}{l}\text { Dispõe sobre a adequada destinação a ser dada aos } \\
\text { medicamentos com prazo de validade vencido, no âmbito do } \\
\text { Estado do Acre. }\end{array}$ \\
\hline Alagoas & Portaria no $63 / 2015$ & $\begin{array}{l}\text { Determinar que o de } \square \text { carte dos medicamentos e correlatos com } \\
\text { validade a expirar seja a ultima circunstância. }\end{array}$ \\
\hline
\end{tabular}




\begin{tabular}{|c|c|c|}
\hline Amapá & Lei no 679/2002 & $\begin{array}{l}\text { Dispõe sobre a distribuição e a destinação de medicamentos cujos } \\
\text { prazos de validade expirem em poder das farmácias e dá outras } \\
\text { providências. }\end{array}$ \\
\hline \multirow[b]{2}{*}{ Amazonas } & Lei no 3.676/2011 & $\begin{array}{l}\text { Cria o Programa Estadual de Coleta de Medicamentos Vencidos ou } \\
\text { Estragados, e fixa outras providências correlatas. }\end{array}$ \\
\hline & Lei no 155/2013 & $\begin{array}{l}\text { Dispõe sobre a responsabilidade de as indústrias farmacêuticas e } \\
\text { de as empresas de distribuição de medicamentos darem } \\
\text { destinação adequada a medicamentos com prazos de validade } \\
\text { vencidos e adota outras providências. }\end{array}$ \\
\hline Ceará & Lei no 15.192/2012 & $\begin{array}{l}\text { Define normas para o descarte de medicamentos vencidos e/ou } \\
\text { fora de uso. }\end{array}$ \\
\hline \multirow[t]{2}{*}{ Distrito Federal } & Lei no $5.092 / 2013$ & $\begin{array}{l}\text { Dispõe sobre a obrigatoriedade de farmácias e drogarias } \\
\text { receberem medicamentos com prazo de validade vencido para } \\
\text { descarte. }\end{array}$ \\
\hline & Lei no $3.401 / 2004$ & $\begin{array}{l}\text { Dispõe sobre o recolhimento de medicamentos impróprios para o } \\
\text { consumo, no Distrito Federal. }\end{array}$ \\
\hline \multirow[t]{2}{*}{ Espírito Santos } & Lei $n^{\circ} 8.471 / 2007$ & $\begin{array}{l}\text { Revoga a Lei no } 7.735 \text {, de } 05.4 .2004 \text {, que dispõe sobre os } \\
\text { procedimentos relacionados à destinação a ser dada aos } \\
\text { medicamentos com prazos de validade vencidos, e dá outras } \\
\text { providências. }\end{array}$ \\
\hline & Lei $n^{0} 7.735 / 2004$ & $\begin{array}{l}\text { Dispõe sobre os procedimentos relacionados à destinação a ser } \\
\text { dada aos medicamentos com prazos de validade vencidos, e dá } \\
\text { outras providências. }\end{array}$ \\
\hline Maranhão & Lei $n^{\circ} 9.727 / 2012$ & $\begin{array}{l}\text { Obriga fabricantes e empresas de distribuição de medicamentos a } \\
\text { procederem à coleta seletiva e destinação adequada de } \\
\text { medicamentos vencidos e implantar política de informação sobre } \\
\text { os riscos causados por esses produtos, no âmbito do Estado, e dá } \\
\text { outras providências. }\end{array}$ \\
\hline \multirow{2}{*}{$\begin{array}{l}\text { Mato Grosso do } \\
\text { Sul }\end{array}$} & Lei $n^{\circ}$ 4.474/2014 & $\begin{array}{l}\text { Dispõe sobre a obrigatoriedade das farmácias e drogarias } \\
\text { manterem recipientes para coleta de medicamentos, cosméticos, } \\
\text { insumos farmacêuticos e correlatos, deteriorados ou com prazo de } \\
\text { validade expirado. }\end{array}$ \\
\hline & Lei no $2.517 / 2002$ & $\begin{array}{l}\text { Dispõe sobre a responsabilidade das indústrias farmacêuticas e } \\
\text { das empresas de distribuição de medicamentos quanto a } \\
\text { destinação adequada à medicamentos com prazos de validade } \\
\text { vencidos, e adota outras providências. }\end{array}$ \\
\hline Pará & $\begin{array}{l}\text { Instrução } \\
\text { Normativa } \quad n^{0} \quad 001 \\
02 / 2015\end{array}$ & $\begin{array}{l}\text { Dispõe sobre normas e rotinas no âmbito do Programa de } \\
\text { Medicamentos do Componente Especializado do Estado do Pará. }\end{array}$ \\
\hline Paraíba & Lei no 9.646/2011 & $\begin{array}{l}\text { Dispõe sobre as normas para a destinação final do descarte de } \\
\text { medicamentos vencidos ou impróprios para uso, no âmbito do } \\
\text { Estado da Paraíba e dá outras providências. }\end{array}$ \\
\hline \multirow{4}{*}{ Paraná } & Lei $n^{0} 17.211 / 2012$ & $\begin{array}{l}\text { Dispõe sobre a responsabilidade da destinação dos medicamentos } \\
\text { em desuso no Estado do Paraná e seus procedimentos. }\end{array}$ \\
\hline & Lei no 16.322/2009 & $\begin{array}{l}\text { Dispõe que é de responsabilidade das indústrias farmacêuticas, } \\
\text { das empresas de distribuição de medicamentos e das farmácias, } \\
\text { drogarias e drugstores, darem destinação final e adequada aos } \\
\text { produtos que estejam com prazos de validade vencidos ou fora de } \\
\text { condições de uso. }\end{array}$ \\
\hline & Lei no 16.107/2009 & $\begin{array}{l}\text { Prevê a entrega voluntária, por pessoas físicas ou jurídicas, de } \\
\text { medicamentos fora do prazo de validade, conforme especifica. }\end{array}$ \\
\hline & Lei $\mathrm{n}^{0}$ 13.039/2001 & Revogada pela Lei $n^{\circ}$ 16.322/2009. \\
\hline Pernambuco & Lei no $14.461 / 2011$ & $\begin{array}{l}\text { Torna obrigatória a existência de recipientes para coleta de } \\
\text { medicamentos, cosméticos, insumos farmacêuticos e correlatos, } \\
\text { deteriorados ou com prazo de validade expirado, e dá outras }\end{array}$ \\
\hline
\end{tabular}




\begin{tabular}{|l|l|l|}
\hline & Lei no 13.065/2006 & $\begin{array}{l}\text { providências. } \\
\text { Dispõe sobre a substituição e destinação de medicamentos cujos } \\
\text { prazos de validade expirem em poder das farmácias e adota outras } \\
\text { providências. }\end{array}$ \\
\hline \multirow{2}{*}{ Piauí } & Lei no 6.287/2012 & $\begin{array}{l}\text { Dispõe sobre a obrigatoriedade das farmácias e drogarias de } \\
\text { manterem recipientes para coleta de medicamentos, cosméticos, } \\
\text { insumos farmacêuticos e correlatos, deteriorados ou com prazo de } \\
\text { validade expirado. }\end{array}$ \\
\hline Sul Grande do & Lei no 13.905/2012 & $\begin{array}{l}\text { Dispões sobre a obrigatoriedade das farmácias e drogarias } \\
\text { manterem recipientes para coleta de medicamentos, cosméticos, } \\
\text { insumos farmacêuticos e correlatos, deteriorados ou com prazo de } \\
\text { validade expirado. }\end{array}$ \\
\hline & Lei no 10.099/1994 & $\begin{array}{l}\text { Dispõe sobre os resíduos sólidos provenientes de serviços de } \\
\text { saúde e dá outras providências. }\end{array}$ \\
\hline Rondônia & Lei no 3.175/2013 & $\begin{array}{l}\text { Autoriza o poder executivo do estado de Rondônia a implantar } \\
\text { pontos de entrega voluntária de medicamentos vencidos e institui a } \\
\text { política de Informações sobre os riscos ambientais causados pelo } \\
\text { descarte incorreto desses produtos. }\end{array}$ \\
\hline Santa Catarina & Lei no 11.190/1999 & $\begin{array}{l}\text { Dispõe sobre a distribuição e a destinação de medicamentos cujos } \\
\text { prazos de validade expirem em poder das farmácias e adota outras } \\
\text { providências. }\end{array}$ \\
\hline Sergipe & $\begin{array}{l}\text { As farmácias e drogarias do Estado de Sergipe ficam obrigadas a } \\
\text { manter recipientes para a coleta de medicamentos, cosméticos, } \\
\text { insumos farmacêuticos e correlatos, deteriorados ou com prazo de } \\
\text { validade expirado. }\end{array}$ \\
\hline
\end{tabular}

Fontes: Assembleias Legislativas e Câmara Legislativa do Distrito Federal, LexML, Casa Civil e Diário Oficial dos Estados e do Distrito Federal. Elaborada pela autora.

O tratamento dado às diferentes matérias abordadas oscilou quanto à profundidade de detalhamento. Considerou-se qualquer menção para incluir o tópico como matéria tratada pela norma (Quadro 2). O conteúdo foi separado em tópicos e subtópicos consubstanciados na PNRS, na MGRSS da Anvisa, na RDC n 306/2004 da Anvisa e na Resolução no 358/2005 do CONAMA. Destacaram-se os responsáveis e a capacitação devido a importância da matéria como ponto estratégico nos planos de gestão de acordo com a PNRS.

Quadro 2 - Matérias tratadas nas leis estaduais sobre logística reversa de medicamentos. Brasil.

\begin{tabular}{|l|l|l|l|l|}
\hline \multicolumn{1}{|c|}{ Norma Jurídica } & \multicolumn{1}{c|}{ Gestão } & Responsáveis & \multicolumn{1}{c|}{ Gerenciamento } & Capacitação \\
\hline Lei $\mathrm{n}^{\circ} 10.099 / 1994$ & $1.3,1.5$ & $2.1,2.2$ & $3.1,3.3,3.4,3.6,3.7$ & - \\
\hline Lei $\mathrm{n}^{\circ} 11.190 / 1999$ & $1.2,1.5$ & $2.1,2.2$ & - & - \\
\hline Lei $\mathrm{n}^{\circ}$ 679/2002 & $1.2,1.4,1.5$ & $2.1,2.2$ & 3.8 & - \\
\hline Lei $\mathrm{n}^{\circ} 1.401 / 2001$ & $1.2,1.3,1.5$ & $2.1,2.2$ & 3.7 & - \\
\hline Lei $\mathrm{n}^{\circ}$ - $2.517 / 2002$ & $1.2,1.5$ & $2.1,2.2$ & - & - \\
\hline
\end{tabular}




\begin{tabular}{|c|c|c|c|c|}
\hline Lei $n^{\circ} 3.401 / 2004$ & $1.5,1.7$ & 2.1 & 3.8 & - \\
\hline Lei no 13.065/2006 & $1.2,1.5,1.7$ & 2.1 & $3.1,3.5$ & - \\
\hline Lei no 16.107/2009 & 1.3 & $2.1,2.3$ & 3.3 & - \\
\hline Lei no 16.322/2009 & $1.2,1.5$ & $2.1,2.2$ & 3.8 & - \\
\hline Lei no 14.461/2011 & $1.5,1.7$ & 2.1, & $3.3,3.4,3.5,3.6$ & 4.2 \\
\hline Lei $n^{0} 3.676 / 2011$ & $1.1,1.4,1.5,1.7$ & $2.1,2.3$ & 3.8 & - \\
\hline Lei no 9.646/2011 & - & $2.1,2.3$ & 3.8 & 4.2 \\
\hline Lei no 13.905/2012 & 1.5 & 2.1, & $3.2,3.3$ & 4.2 \\
\hline Lei no $17.211 / 2012$ & $1.5,1.7$ & $2.1,2.3$ & $3.3,3.5,3.6,3.7,3.8$ & 4.2 \\
\hline Lei no 15.192/2012 & 1.1 & $2.1,2.3$ & $3.2,3.3$ & 4.2 \\
\hline Lei $n^{0} 9.727 / 2012$ & $1.2,1.4,1.6$ & $2.1,2.3$ & 3.2 & 4.2 \\
\hline Lei no 6.287/2012 & 1.5 & 2.1, & $3.2,3.3$ & 4.2 \\
\hline Lei $n^{0} 5.092 / 2013$ & - & $2.1,2.3$ & $3.4,3.5,3.6$ & - \\
\hline Lei no 155/2013 & 1.2, 1.5, & $2.1,2.3$ & - & - \\
\hline Lei no 2.720/2013 & $1.1,1.4,1.5,1.7$ & $2.1,2.3$ & 3.8 & - \\
\hline Lei $n^{0} 3.175 / 2013$ & - & 2.1 & - & - \\
\hline Lei no 4.474/2014 & 1.5 & 2.1 & $3.2,3.3,3.5,3.8$ & 4.2 \\
\hline Lei no $7913 / 2014$ & 1.5 & 2.1 & $3.2,3.3,3.5,3.8$ & 4.2 \\
\hline Portaria no 63/2015 & $1.1,1.3,1.5$ & 2.1 & $3.1,3.7,3.8$ & - \\
\hline IN № $00102 / 2015$ & $1.1,1.5$ & $2.1,2.3$ & $3.1,3.5$ & - \\
\hline
\end{tabular}

Fonte: Elaborada pela autora. LEGENDA: 1. Gestão: 1.1 Metas/ Diretrizes/ Princípios/ Objetivos, 1.2 Definições, 1.3 Acordos setoriais/ Integração de regiões, 1.4 Investimento/ Financiamento, 1.5 Monitoramento, Avaliação e Controle/ Fiscalização/ Penalidade, 1.6 Sistema de informação, 1.7 Regulamentação/ Regularizar, 1.8 Estudos e pesquisas 2. Setores responsáveis: 2.1 Quem/ Responsabilidades, 2.2 Garantias, 2.3 Participação da sociedade civil. 3. Gerenciamento dos resíduos: 3.1 Recuperação/ Reutilização/ Reciclagem, 3.2 Recolhimento/coleta, 3.3 Acondicionamento, 3.4 Forma de segregação, 3.5 Armazenamento, 3.6 Transporte, 3.7 Tratamento, 3.8 Disposição final. 4. Capacitação: 4.1 Treinamento/ Educação continuada, 4.2 Programa de conscientização/ cartazes.

Existem dois padrões de assunto que não se confundem: enquanto as leis anteriores a 2009 determinam o compromisso entre indústria e comércio, quando o medicamento vencido, deteriorado ou prestes a vencer está ainda em poder das farmácias, as leis advindas a partir de 2009 inovam na cadeia de incumbências, responsabilizando o consumidor como corresponsável pela devolução dos medicamentos já comercializados.

Verifica-se o incentivo à produção de normas concorrentes estaduais nos anos posteriores a 2010, com o advento da PNRS, dado que 12 normas, $48 \%$, se concentram entre os anos de 2011 a 2013.

Algumas leis apresentaram teores similares. A Lei no 2.720/2013, do Acre, e a Lei no 3.676/2011, do Amazonas, têm a mesma redação, assim como acontece com a Lei no 6.287/2012, do Piauí, e a Lei no 13.905/2012, do Rio Grande do Sul, cuja única distinção 
consiste em que esta apresenta Vacatio legis. É certo que não se pode justificar as semelhanças em razão de peculiaridades locais, uma vez que se referem a condições ambientais, de desenvolvimento institucional e de mercado muito distintas.

Em geral, as normas foram silentes em matérias relevantes. Pouco se falou sobre os objetivos e metas, integração entre regiões, financiamento, sistema de informação, etapas do gerenciamento de resíduos de forma objetiva e capacitação. Contudo, quando manifesto, os assuntos foram mais recorrentes nas normas produzidas nos anos após a instituição da PNRS.

Destaca-se, dos conteúdos mais explorados, a definição dos responsáveis, suas obrigações - presente em todas as normas - além do controle, avaliação e monitoramento - presente em $72 \%$ dos textos legais.

Quanto à técnica legislativa, a falta de revogação expressa prejudica a relação do encadeamento das normas. A redação do texto também deixa a desejar na precisão técnica.

Mesmo ciente que as normas subsequentes à PNRS se referem à devolução do medicamento pelo cliente, sete não determinam expressamente esta obrigatoriedade. Em sua maioria, não se explica o modo como cada etapa do gerenciamento será realizada, deixa-se subentendido ou transfere-se o detalhamento para "normas específicas". Os tópicos e subtópicos da tabela 1 correspondem a assuntos relevantes, consoantes com as leis vigentes que embasaram a produção das normas. A acusação de que certa norma referencia determinado subtópico não implica que as normas que a fizeram discorreram de forma semelhante o assunto.

Tabela 1 - Matérias tratadas pelas normas estaduais sobre logística reversa de medicamentos. Brasil. 1994-2015.

\begin{tabular}{l|rr}
\hline \multicolumn{1}{c|}{ Matéria } & № & \% \\
\hline 1. Gestão & 22 & 88 \\
1.1 Metas/Diretrizes/Princípios/Objetivos & 5 & 20 \\
1.2 Definições & 9 & 36 \\
1.3 Acordos setoriais/Integração de regiões & 4 & 16 \\
1.4 Investimento/Financiamento & 4 & 16 \\
1.5 Monitoramento/Avaliação/Controle/Fiscalização/Penalidades & 18 & 72 \\
1.6 Sistema de informação & 1 & 4
\end{tabular}


1.7 Regulamentação/Regulação

1.8 Estudo e Pesquisa

2. Setores responsáveis

2.1 Quem/Responsabilidades

2.2 Garantias

2.3 Participação da sociedade civil

\section{Gerenciamento dos resíduos}

3.1 Recuperação/Reutilização/Reciclagem

3.2 Recolhimento/Coleta

3.3 Acondicionamento

3.4 Forma de segregação

3.5 Armazenamento

3.6 Transporte

3.7 Tratamento

3.8 Disposição final

\section{Capacitação}

4.1 Treinamento/Educação Continuada

4.2 Programa de conscientização/cartazes

Total

Fonte: Elaborada pela autora.

$\mathrm{Na}$ análise de mérito (Tabela 1), no que se refere à gestão, cinco (20\%) falaram sobre o objetivo principal da norma como conscientizar, sensibilizar a população, evitar desperdício e intoxicação, promover a padronização das atividades e melhorar a qualidade de atendimento prestado a população. Três (12\%) citaram investimento/ financiamento como dotação orçamentária própria. Nove (36\%) trazem definições de agentes e/ou de produtos. Apenas três incentivam a gestão regionalizada como permutação de produtos ou realização de convênios com órgão e entidades da sociedade civil. Já a Lei no 14.01/2001, do Acre, vai de encontro a este preceito ao dispor, de forma coercitiva e não colaborativa, que empresas industriais de outro estado são responsáveis pelo gerenciamento do medicamento.

$\mathrm{Na}$ Gestão, das 25 normas encontradas, 11 (44\%) dispunham sobre controle, avaliação e monitoramento, sendo que cinco $(20 \%)$ tratam a matéria com idêntico teor: "embalagens devem estar acompanhadas de um relatório, contendo o nome fantasia dos produtos, o nome técnico, a quantidade, o lote, o fabricante e o motivo pelo qual não podem ser utilizados". Outros seis $(24 \%)$ variaram entre autorização, prévia análise, 
justificativa e emissão de nota fiscal para devolução. Quatro (16\%) tratam da fiscalização e esclarecem que a fica a cargo da vigilância sanitária esta supervisão. A Lei no 10.099/1994, do Rio Grande do Sul, compartilha a competência com o órgão estadual do meio ambiente, assim como a Lei oㅜ 17.211/2012, do Paraná, que inclui o Instituto Ambiental do Paraná no encargo de fiscalizar. E a Lei no 10.099/1994, do Rio Grande do Sul, determina haver prazo para regularização.

Quatorze (56\%) normas estaduais estabelecem penalidades pelo descumprimento, sendo que sete detalham-nas. As multas variam ente o valor de $200 \%$ do preço atualizado do medicamento e a escala de valores de 100 a 10.000 Unidade de Padrão Fiscal do Estado. As demais remetem a penalidades previstas na legislação sanitária e ambiental. Oito (32\%) falam sobre reincidência.

A estipulação para maiores regulamentações por outras normativas é mencionada em seis (24\%) normas, cujo prazo variou entre 60 a 180 dias. A regulamentação, a cargo do Executivo, é pertinente, mediante o tratamento superficial do conteúdo material da norma. Mas não é necessária explicitá-la nem estabelecer prazos. Pois isso é inconstitucional com base no princípio da independência dos Poderes (art. $2^{\circ}, \mathrm{CF} / 88$ ).

Todas as normas determinaram os responsáveis, sendo que 20 estabeleceram a responsabilidade do comércio em dispor de recipiente para o recolhimento dos produtos ou em informar ao distribuidor para a devolução quando em seu poder. Os demais incumbiram ao poder público o dever de coletar (Instrução Normativa № 001 02/2015, do Pará; a Portaria no 63/2015, de Alagoas; a Lei no 3.175/2013, de Rondônia, e a Lei no 16.107/2009, do Paraná). Apenas a Lei no 17.211/2012, do Paraná, atribui responsabilidade a esfera pública e privada.

A maior parte utiliza farmácias e drogarias como ponto de coleta. Método similar ao utilizado pelos Estados-membros da União Europeia (2). Outro ponto interessante é a Lei no 5.092/2013, do Distrito Federal, que garante o não prejuízo do setor comercial ao, expressamente, estabelecer a não concessão de desconto pela devolução dos produtos aos clientes.

$\mathrm{Na}$ relação entre distribuidores e estabelecimentos comerciais, quatro (16\%) normas asseguram ao comércio o não recebimento do medicamento cujo prazo de validade tenha decorrido em 1/3 (um terço), salvo se as empresas de distribuição assegurarem imediata 
substituição. Ainda há a garantia de restituição monetária caso o medicamento não seja mais fabricado.

De modo geral, a parte que trata do gerenciamento dos resíduos é bem precária quanto à clareza e objetividade do que é proposto. Nenhuma norma tratou a questão de forma plena. A que mais alcança o mérito é a Lei no 17.211/2012, do Paraná, que, ainda assim, subtrai pontos importantes como a preferência pelo reaproveitamento, alterativa possível conforme a PNRS. Neste caso, seria pertinente, visto que esta normativa se refere a medicamentos em desuso e não somente a medicamentos vencidos como acontece em 21 (84\%) das 25 normas. As quatro (16\%) restantes, além de abordarem os de prazo de validade expirados, incluem medicamento não utilizados, Lei no 10.099/1994, do Rio Grande do Sul; em desuso, Lei no 17.211/2012, do Paraná; sobra de tratamento, Lei no 9.727/2012, do Maranhão; e medicamentos próximo ao vencimento poderem ser remanejados para outras unidades, Instrução Normativa № 001 02/2015, do Pará.

O destaque dentro desta análise é o recolhimento, acondicionamento e armazenamento. Enquanto sete (28\%) normas tratam do recolhimento, quatro expressam os mesmos dizeres: "recipiente lacrado, material impermeável, com abertura superior. Local visível e fácil acesso acompanhado de cartazes...”. O mesmo acontece com o acondicionamento, com os dizeres: "em caixas impermeáveis, com lacre assinado pelo farmacêutico responsável pelo estabelecimento, permanecendo guardadas em local seguro, afastadas das prateleiras e dos clientes".

O destaque neste ponto é a Lei $\mathrm{n}^{0}$ 17.211/2012, do Paraná, que orienta que a embalagens devem ser invioláveis, estanques, resistentes a impactos ou ruptura, acesso inviolável, identificada conforme a NBR 7500, com identificação: "medicamento vencido", localizada nos salões de comercialização ou recepção dos estabelecimentos. Salienta ainda proibição do esvaziamento ou reembalagem de medicamento em qualquer fase do processo. Essa lei se destaca ao determinar a forma de segregação, armazenamento e transporte de forma mais específica. Já a Lei no 4.474/2014, do Mato Grosso do Sul, assegura que o armazenamento deverá ser um local seguro, afastadas das prateleiras e dos clientes.

Mas ao se tratar de disposição final, a Lei nº 17.211/2012, do Paraná, a mais completa na questão técnica, elenca tão somente proibições como lançamento in natura 
ou queima a céu aberto, em corpos d'água, em aterros sanitários que não sejam de classe I, para resíduos perigosos, e em rede de esgoto. A Lei no 9.646/2011, da Paraíba, é que inova sobre o assunto ao sugerir, além de incineração, a destinação final em aterro sanitário especializado. Uma das possíveis causas para a supressão da orientação pelo correto descarte deve-se a falta de aterros sanitários ou incineradores adequados com medidas necessárias para conter a contaminação.

Por fim, a capacitação é uma das matérias mais precariamente discutidas, percebese a displicência em tratar deste tópico. Incluiu-se, nesta área, a advertência em cartazes, acompanhados dos recipientes de coleta, orientando a importância do destino correto dos materiais com epígrafes: "Proteja o meio ambiente", "Deposite aqui medicamentos e outros produtos farmacêuticos deteriorados ou com prazo de validade vencido", "devolva aqui os medicamentos vencidos ou deteriorados", "Evite intoxicação ou contaminação do meio ambiente".

Seria interessante adotar mais formas de intervenção para conscientizar e capacitar a população, porque a educação é a ferramenta ideal para modificar comportamento. Poder-se-ia adotar, como na França, com o Cyclamed, um programa que utiliza emissoras de rádio e televisão para instruir a população ao descarte correto (2). Justifica o nível de detalhamento da lei do Paraná, em discorrer sobre a temática, pelo estado se atentar ao descarte de medicamento desde 2001, tendo publicado quatro leis nesta área.

Percebe-se que nenhuma das normas contempla, em sua plenitude, o conjunto de tópicos necessário à regulamentação da matéria de forma clara e objetiva. Existem inconstâncias - como a Lei no 14.461/2011, de Pernambuco - que não alcança os laboratórios públicos que produzem e comercializam medicamentos. A Lei no 5.092/2013, do Distrito Federal, estabelece que a segregação, armazenamento e transporte fica a critério do farmacêutico. Além da lacuna quanto à escassez na questão da capacitação e da falta de sistema de informação sendo que este apenas a Lei no 9.727/2012, do Maranhão menciona.

Dos estados que não possuem normativa concorrente sobre a matéria, o Mato grosso, apesar de não regulamentar sobre o tema, classifica medicamento e imunoterápicos vencidos ou deteriorados como resíduos de serviço de saúde pela Lei no 7.862, de 19 de dezembro de 2002 que dispõe sobre a Política Estadual de Resíduos 
Sólidos. Contudo, esta e a Política Estadual de Medicamentos, criada pela Lei ํㅜ 7.968, de 25 de setembro de 2003, não trataram de descarte. O Espírito Santos, diante de ter apenas revogado lei anterior sem nova regulamentação, retrocede na discussão por deixar em aberto o assunto que outrora fora regulamentado.

Bahia, Goiás, Mato Grosso, Minas Gerais, Rio de Janeiro, Rio Grande do Norte, São Paulo e Tocantins são estados dos quais não se encontraram normas. Porém a maioria conta com a participação voluntária da iniciativa privada para o descarte pós consumo. Em São Paulo, duas grandes redes de farmácias recebem os medicamentos a serem descartados. Outros programas como Programa Descarte Correto de Medicamentos, Programa Descarte inteligente, Programa Descarte Consciente compensam os estados sem regulamentação. No geral, as indústrias fornecem manutenção dos recipientes para acondicionamento e as farmácias pagam o transporte e o tratamento.

Ao que se refere a atitude a nível federal, é nítida a falta de integração na articulação entre os dois setores emblemáticos que discutem o tema. As gestões da saúde e do meio ambiente têm dificuldade em acordar. Por outro lado, está em curso o acordo que vai implantar coleta e restituição dos resíduos ao setor, com responsabilização das empresas pelo reaproveitamento e destinação ambientalmente adequada aos produtos recolhidos. Tramita no Congresso Nacional o Projeto de Lei $n^{\circ} \mathbf{2 . 1 2 1}$, de 2011, que obriga a rede farmacêutica a se responsabilizar pelo descarte.

O desafio maior é concatenar a responsabilidade de cada setor com etapas do processo de destinação destes resíduos. É importante comprometer outros setores além da cadeia produtiva, como o usuário, a mídia. Justificar a dificuldade de se resolver o problema pela forte influência do setor empresarial vai de encontro com a disposição da iniciativa privada em implementar voluntariamente os pontos de coleta com medicamento.

\section{Conclusão}

Apesar do avanço legislativo, todas as normas estaduais variaram quanto à clareza e profundidade do tratamento das diferentes matérias envolvidas, de forma que nenhuma é completa. Poucas fazem referência expressa à PNRS, ao MGRSS, à RDC no 306/2004 da 
Anvisa ou à Resolução nº 358/2005 do Conama. Existem insuficiências mesmo nas mais inovadoras.

Não foi levado em conta o motivo para a autonomia em legislar concorrentemente concedida aos estados, qual seja atender a peculiaridades locais. Percebeu-se que alguns estados se utilizaram dessa liberdade para duplicar normativas alheias.

Encontrou-se normas de 1994 a 2015, que, de forma geral, contém duas abordagens distintas. Até 2009 falava-se do compromisso entre indústria e estabelecimento. Com o advento da PNRS, o conteúdo substantivo da norma obteve outro sentido, qual seja a instrução da logística reversa para todo o setor de produção, imputando responsabilidade a todos os agentes envolvidos, inclusive o consumidor.

A parte das normas estaduais que trata de gestão é fraca no que diz respeito a investimento, acordos setoriais, sistema de informação e pesquisa. As etapas de gerenciamento de resíduos sólidos são raramente descritas de forma específica, dado que, quando manifestas, indicam apenas que o processo deve ser adequado. Apenas uma das normas indica aterro sanitário especializado como a destinação final adequada. Quase nada se fala em educar os atores, por exemplo, valer-se do Programa Saúde da Família (PSF) para ensinar a população, ou usar a mídia.

$\mathrm{Na}$ grande maioria dos estados, o estabelecimento farmacêutico está responsável por receber o medicamento pós consumo - em geral, apenas produtos vencidos, mas alguns já se mobilizaram para receber sobras de tratamento e medicamento em desuso, que poderiam ser doados e/ou reaproveitados. Alguns estados, no entanto, já se modernizaram a respeito, e ampliaram a responsabilidade para estabelecimentos públicos em serviço de saúde. Neste caso, seria conveniente que a norma previsse a possibilidade da parceria público-privado.

A qualidade da legislação estadual concorrente sobre descarte de medicamento está aquém das expectativas. As inovações reconhecidas pelo estudo poderiam ser incorporadas em todas as normas estaduais. Seria necessária uma intervenção mais minuciosa sobre os quatro temas destacados, para promover as significativas mudanças necessárias. Diante destas observações, espera-se que este estudo traga contribuições que possam nortear os demais entes federados na elaboração de normas posteriores sobre a matéria. 


\section{Referências}

1 Falqueto E, Kligerman DC, Assumpção RF. Como realizar o correto descarte de resíduos de medicamentos? Ciênc. Saúde coletiva (2010), 15(2):3283-3293. [Acesso em 15 set. 2015]. Disponível em: http://ref.scielo.org/t5k95t

2 Agência Brasileira de Desenvolvimento Industrial. Logística Reversa para o Setor de Medicamento. Brasília: Agência Brasileira de Desenvolvimento Industrial, 2013. [Acesso em: 15 set. 2015]. Disponível em:

http://portal.anvisa.gov.br/wps/wcm/connect/6035fe804362f6fbaca0be0eb77d2a7a/Log\%C 3\%ADstica+Reversa+de+Medicamentos.pdf?MOD=AJPERES

3 Falqueto E, Kligerman DC, Assumpção RF. Diretrizes para um Programa de Recolhimento de Medicamentos Vencidos no Brasil. Ciênc. Saúde Coletiva, 2013, 18(3): 883-892. [Acesso em 23 nov. 2015]. Disponível em: http://ref.scielo.org/t7wp37 .

4 Eickhoff $P$, Heineck I, Seixas LJ. Gerenciamento e destinação final de medicamentos: uma discussão sobre o problema. Rev Bras Farm, 2009, (1): 64-68. [Acesso em 14 set. 2015]. Disponível em: http://rbfarma.org.br/files/pag 64a68 208 gerenciamento destinacao.pdf

5 Alencar TOS, Machado CSR, Costa SCC, Alencar BR. Descarte de medicamentos: uma análise da prática no Programa Saúde da Família. Ciênc. Saúde Coletiva, 2014, (19): 2157-2166. [Acesso em 14 set. 2015]. Disponível em: http://www.redalyc.org/articulo.oa?id=63031150019

6 Agência Nacional de Vigilância Sanitária (ANVISA). Resolução da Diretoria Colegiada $n^{\circ}$ 306, de 7 de dezembro de 2004. Dispõe sobre o Regulamento Técnico para o Gerenciamento de Resíduos de Serviços de Saúde. Diário Oficial da União [da] República Federativa do Brasil. (10 dez. 2004); Seção 1, 49-56.

7 Gasparini JC, Gasparini AR, Frigieri MC. Estudo do descarte de medicamentos e consciência ambiental no município de Catanduva-SP. Ciência \& Tecnologia, 2011, 2(1):38-51. [Acesso em 10 set. 2015]. Disponível em: http://www.citec.fatecjab.edu.br/index.php/files/article/viewFile/10/11

8 Araújo K, Neves M, Sá M, Silva L, Brito N. Fármacos residuais: um problema de caráter ambiental. In: V Congresso de Pesquisa e Inovação da Rede Norte-Nordeste de Educação Tecnológica. 2010. [Acesso em 13 set. 2015]. Disponível em: http://connepi.ifal.edu.br/ocs/index.php/connepi/CONNEPI2010/paper/viewFile/1418/467

9 Habert A C. Fronteiras da engenharia química. Rio de Janeiro: E-papers Serviços Editoriais, 2005.

10 Suchara EA. Desenvolvimento de metodologias analíticas para determinação de fármacos em fluidos biológicos e amostras ambientais por cromatografia líquida e gasosa [Dissertação]. Florianópolis: Programa de Pós-Graduação em Química, Universidade Federal de São Catarina; 2007. [Acesso em 10 set. 2015].Disponível em: 
https://repositorio.ufsc.br/bitstream/handle/123456789/90022/227418.pdf?sequence=1

11 Agência Nacional de Vigilância Sanitária (ANVISA). Manual de Gerenciamento de Resíduos de Serviços de Saúde. Brasília: Ministério da Saúde. 2006.

12 Brasil. Lei no 12.305, 2 de agosto de 2010. Institui a Política Nacional de Resíduos Sólidos. Diário Oficial da União [da] República Federativa do Brasil. (3 ago. 2010); Seção 1, 3-7.

13 Brasil. Decreto № 7.404, 23 de dezembro de 2010. Regulamenta a Lei no 12.305, de 2 de agosto de 2010, que institui a Política Nacional de Resíduos Sólidos, cria o Comitê Interministerial da Política Nacional de Resíduos Sólidos e o Comitê Orientador para a Implantação dos Sistemas de Logística Reversa, e dá outras providências. Diário Oficial da União [da] República Federativa do Brasil. (23 dez. 2010); Seção 1, 1-6.

14 Barcellos RMG, Sinoti, ALL, Oliveira MC, Ribeiro CM, Santana ES, Cavalcante RAFC, Neves ELTN, Leite FQ, Rodero SOR, Martinello ML, Miranda MA, Farza HR, Mesiano RAB, Dutra CY, Zardin VG, Coura FM, Ribas S, Alves FNR, Benevides Filho AN, Silva GHT. Descarte de medicamento Responsabilidade compartilhada [Internet]. In: I Semana de Vigilância Sanitária; 8-10 maio 2012, Brasília: Congresso Nacional; 2012. [Acesso em 22 dez. 2015]. Disponível em:

http://portal.anvisa.gov.br/wps/wcm/connect/81588400474586d89032d43fbc4c6735/Apres entac\%CC\%A7a\%CC\%83o+Anvisa.ppt?MOD=AJPERES

15 Ministério do Meio Ambiente. Sistema Nacional de Informações sobre a Gestão dos Resíduos Sólidos, SINIR. Brasília, 2010. [Acesso em 21 set. 2015]. Disponível em: http://www.sinir.gov.br/web/guest/logistica-reversa

16 Ministério do Meio Ambiente. Resolução Conama no 358, 29 de abril de 2005. Dispõe sobre o tratamento e a disposição final dos resíduos dos serviços de saúde e dá outras providências. Diário Oficial da União [da] República Federativa do Brasil. (4 maio 2005); Seção 1, 63-65.

17 Drigo LG. Competências legislativas concorrentes: o que são normas gerais? Revista Jus Navigandi, 2013. [Acesso em 13 nov. 2015]. Disponível em:

http://jus.com.br/artigos/24557

18 Brasil. Constituição (1988). Constituição da República Federativa do Brasil. Brasília, DF: Senado Federal, 2015.

\section{Como citar este artigo:}

Torres ACG. Pertinência da normativa estadual e distrital sobre logística reversa aplicada ao setor de medicamentos no Brasil. Revista Cadernos Ibero-Americanos de Direito Sanitário. 2016 jan./mar, 5(1):41-59. 